\title{
A ATIVIDADE MICROBIOLÓGICA DO SOLO É INFLUENCIADA PELA ROTAÇÃO DE CULTURAS?
}

\author{
Eduardo Henrique Lima Mazzuchelli', Flávia Alessandra Mignacca', Fábio Fernando Araújo², Melina \\ Daniel Rebonatti ${ }^{1}$, Carlos Sérgio Tiritan ${ }^{2}$ \\ Universidade do Oeste Paulista - UNOESTE, Programa de Pós-Graduação em Agronomia, Presidente Prudente, SP. E- \\ mail: eduardomazuchelli@yahoo.com.br
}

\section{RESUMO}

O objetivo do trabalho foi avaliar a produtividade da soja, fertilidade e microbiologia do solo submetido a diferentes rotações de cultura na entressafra da soja. O experimento foi desenvolvido na Fazenda Experimental da UNOESTE, em Presidente Bernardes - SP, utilizando rotação de culturas de entressafra, com seis tratamentos, sendo eles, milheto, pastagem semeada, milho, sorgo, girassol e feijão guandu. O delineamento experimental foi em faixas, com quatro repetições cada. As analises microbiológicas foram coletadas de $0-10 \mathrm{~cm}$ de profundidade, realizou-se também análise de fertilidade do solo, na profundidade de $0-20 \mathrm{~cm}$. A atividade microbiológica do solo apresentou melhorias após o cultivo de girassol e feijão guandu. A produtividade da soja foi influenciada pelo uso de plantas de entressafra, apresentando incremento após milheto no primeiro ano e sorgo no segundo ano de cultivo. Os parâmetros de fertilidade do solo não foram influenciados com o uso das plantas de entressafra.

Palavras-chave: Entressafra da soja, Milheto, Sorgo, Guandu, Girassol,

\section{THE MICROBIOLOGICAL ACTIVITY OF THE SOIL IS INFLUENCED BY THE ROTATION OF CULTURES?}

\begin{abstract}
The objective of this work was to evaluate the soybean yield, fertility and microbiology of the soil submitted to different crop rotations in the soybean off season. The experiment was carried out at the Experimental Farm of UNOESTE, in Presidente Bernardes - SP, using crop rotation, with six treatments, including millet, sown pasture, corn, sorghum, sunflower and pigeon pea. The experimental design was in bands, with four replicates each. The microbiological analyzes were collected from 0-10 cm depth, soil fertility analysis was also performed, at 0-20 cm depth. The microbiological activity of the soil showed improvements after the cultivation of sunflower and pigeon pea. The soybean yield was influenced by the use of off - season plants, presenting an increase after millet in the first year and sorghum in the second year of cultivation. Soil fertility parameters were not influenced by the use of off-season plants.
\end{abstract}

Keywords: Soybean off season, Millet, Sorghum, Cajanus cajan, Sunflower.

\section{INTRODUÇÃO}

Para um desenvolvimento pleno das culturas, é preciso que os solos cultivados possuam equilíbrio em sua comunidade microbiológica. $O$ uso consciente do solo agrícola, além de aumentar a produtividade das plantas, tem por consequência diminuição dos impactos ambientais e melhora dos atributos microbiológicos do solo, além de manter ou melhorar sua fertilidade. A biomassa microbiana do solo (BMS), é parte importante na manutenção e produtividade dos 
ecossistemas agrícolas e florestais, é um parâmetro na caracterização da qualidade do solo em áreas sob diferentes regimes de manejo e cultivo (COSTA et al, 2013).

A rotação de culturas com plantas de cobertura influencia diretamente os atributos biológicos do solo, sendo o sistema de plantio direto um preservador do carbono da biomassa microbiana (SILVA et al, 2007).

O objetivo do trabalho foi avaliar a produtividade da soja, fertilidade e microbiologia do solo submetido a diferentes rotações de cultura na entressafra da soja.

MATERIAL E MÉTODOS

O experimento foi instalado em fevereiro de 2015 e conduzido a campo na Fazenda Experimental da Universidade do Oeste Paulista - UNOESTE, em Presidente Bernardes-SP, em um Argissolo Vermelho distroférrico (Embrapa, 2013), com relevo suave ondulado e teor de argila de $160 \mathrm{~g}$ ha-1 na camada de $0-20 \mathrm{~cm}$. O clima da região de Presidente Prudente-SP, segundo a classificação de Köppen, é do tipo Cwa, com temperaturas médias anuais em torno de $25^{\circ} \mathrm{C}$ e regime pluvial caracterizado por período chuvoso de outubro a março e outro de baixa precipitação pluvial de abril a setembro.

Em 2015 foram coletadas amostras para caracterização química do solo nas camadas de 020 e 20-40. Embasada na análise de solo, foi realizada a correção do solo. Utilizou-se o calcário dolomítico com $286 \mathrm{~g} \mathrm{~kg}^{-1}$ de $\mathrm{CaO}, 163 \mathrm{~g} \mathrm{~kg}^{-1}$ de $\mathrm{MgO}$ e PRNT de 84\%, na dose de $1800 \mathrm{~kg} \mathrm{ha}^{-1}$. Utilizou-se o gesso agrícola com as seguintes características: $260 \mathrm{~g} \mathrm{~kg}^{-1}$ de CaO e $150 \mathrm{~g} \mathrm{~kg}^{-1} \mathrm{de} \mathrm{S}$, na dose de $1000 \mathrm{~kg} \mathrm{ha}^{-1}$. Foram aplicados 10,75 e $25 \mathrm{~kg} \mathrm{ha}^{-1}$ de $\mathrm{N}, \mathrm{K}_{2} \mathrm{O}$ e $\mathrm{P}_{2} \mathrm{O}_{5}$, respectivamente, em formulação NPK com micronutrientes.

Antes da instalação do experimento, havia a presença de pastagem degradada de Urochloa brizantha, que foi dessecada com 30 dias de antecedência, utilizando o herbicida Glyphosate, na dose de $5 \mathrm{~L} \mathrm{ha}{ }^{-1}$ do produto comercial, para a semeadura das culturas de entressafra.

A área experimental foi dividida em faixas de 6,3 m (L) por $100 \mathrm{~m}$ (C), onde foram semeadas as culturas de inverno, caracterizando os seguintes tratamentos: T1- Milheto; T2Pastagem semeada (Urochloa brizantha cv. Marandu); T3- Milho; T4- Sorgo; T5- Girassol; T6Guandu. Os tratamentos aplicados seguem delineamento experimental em faixas, com quatro repetições cada.

Quando as culturas atingiram ponto de silagem, foi realizada a colheita, simulando a colheita de planta inteira para silagem. E quatro meses após, a soja foi semeada, sendo o cultivar BMX Potência RR, no espaçamento de 0,45 m entrelinhas e 17 sementes por metro linear. Quando a soja atingiu o ponto de colheita, foram coletadas seis linhas de um metro de comprimento de cada unidade experimental, corrigido o teor de água nos grãos a $13 \%$ e com isso determinada a produtividade em $\mathrm{mg} \mathrm{ha}^{-1}$. Após a colheita da soja, em 2016, foi realizada novamente a rotação de culturas, para novo ciclo de avaliação idêntico ao ano anterior.

Ao final do ciclo das culturas de entressafra, por volta do mês de agosto dos dois anos agrícola, o solo foi coletado na profundidade de $0-20 \mathrm{~cm}$, e analisado conforme metodologias descritas por Raij et al. (2001).

A coleta de amostras para análises microbiológicas foi realizada em de março de 2017, sendo coletadas na profundidade de $0-10 \mathrm{~cm}$, e encaminhadas ao laboratório de Microbiologia do Solo, no Campus II da UNOESTE, onde foram peneiradas em malha de $2 \mathrm{~mm}$ e secas em estufa

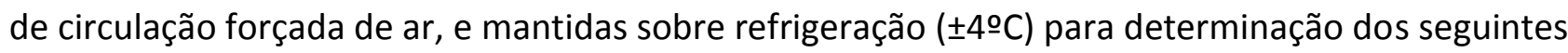
parâmetros: carbono e nitrogênio da biomassa microbiana do solo (CBMS e NBMS) conforme a metodologia descrita por Ferreira et al, (1999), carbono orgânico estimado através do calculo da matéria orgânica do solo, a respiração basal do solo conforme metodologia de Jenkinson e Powlson (1976), quociente metabólico $\left(q \mathrm{CO}_{2}\right)$, sendo a razão entre o $\mathrm{C}-\mathrm{CO}_{2}$ liberado pela respiração do solo pelo $\mathrm{C}$ na biomassa microbiana, expresso em $\mathrm{mg} \mathrm{C}-\mathrm{CO}_{2}$ g-1 $\mathrm{BMS}-\mathrm{Ch}^{-1}$ (ANDERSON; DOMSCH, 1993) e quociente microbiano (qMic) sendo a razão entre a biomassa 
microbiana do solo e o carbono orgânico do solo, expresso em $\mathrm{mg} \mathrm{C}^{-\mathrm{CO}_{2}} \mathrm{mg} \mathrm{Cmic}^{-1}$ (SPARLING, 1992). Atividade das enzimas desidrogenase segundo metodologia de Van Os e Ginkel (2001) e fosfatase ácida de acordo com Tabatabai e Bremner (1969).

Os dados foram submetidos à análise de variância e comparação entre médias pelo teste de Tukey a 1 e $5 \%$ de probabilidade, utilizando o programa estatístico SISVAR.

RESULTADOS

Segundo a tabela 1 , os teores de fertilidade do solo na profundidade de $0-20 \mathrm{~cm}$ não apresentaram diferença significativa entre si, de acordo com os tratamentos empregados.

Tabela 1. Análise de Solos na profundidade de 0-20 cm, Presidente Bernardes - SP, 2016.

\begin{tabular}{cccccccc}
\hline Tratamento & $\mathrm{pH}\left(\mathrm{CaCl}_{2}\right)$ & $\mathrm{M} . \mathrm{O}$. & $\mathrm{P}$ & $\mathrm{S}-\mathrm{SO} 4^{2-}$ & $\mathrm{K}$ & $\mathrm{Ca}$ & $\mathrm{Mg}$ \\
\hline Milheto & & $\left(\mathrm{g} \mathrm{dm}^{-3}\right)$ & \multicolumn{2}{c}{$\left(\mathrm{mg} \mathrm{dm}^{-3}\right)$} & & \multicolumn{2}{c}{$\left(\mathrm{mmol}_{\mathrm{c}} \mathrm{dm}^{-3}\right)$} \\
Urochloa brizantha & 4,9 & 13,0 & 4,9 & 7,9 & 0,8 & 8,8 & 4,4 \\
Milho & 4,7 & 13,4 & 4,4 & 5,4 & 0,6 & 5,3 & 3,7 \\
Sorgo & 4,7 & 12,5 & 2,0 & 6,4 & 1,1 & 6,1 & 4,5 \\
Girassol & 4,3 & 11,3 & 3,3 & 18,5 & 0,5 & 5,1 & 3,1 \\
Guandu & 4,4 & 12,1 & 3,7 & 10,2 & 0,5 & 5,4 & 4,0 \\
\hline F & 4,2 & 11,0 & 4,3 & 16,8 & 0,4 & 4,3 & 2,4 \\
\hline CV(\%) & $2,63^{\mathrm{ns}}$ & $1,09^{\mathrm{ns}}$ & $0,95^{\mathrm{ns}}$ & $2,28^{\mathrm{ns}}$ & $1,21^{\mathrm{ns}}$ & $2,28^{\mathrm{ns}}$ & $0,81^{\mathrm{ns}}$ \\
\hline
\end{tabular}

Médias seguidas pelas mesmas letras não diferem estatisticamente entre si pelo teste Tukey $(p<0,005)$

A produtividade de grãos de soja foi influenciada nos dois anos de cultivo, conforme a adoção das plantas de entressafra (Tabela 2). Na safra de 2015/16, a maior produtividade foi observada após o cultivo de milheto em relação às faixas anteriormente cultivadas com sorgo e girassol, respectivamente.

Na safra seguinte, a maior produtividade de grãos de soja foi obtida após o cultivo de sorgo em relação à faixa cultivada anteriormente com Urochloa brizantha.

Tabela 2. Produtividade de grãos de soja ( $\mathrm{kg} \mathrm{ha}^{1}$ ) com umidade corrigida a $13 \%$ em dois anos de cultivo, no município de Presidente Bernardes - SP.

\begin{tabular}{ccc}
\hline \multirow{2}{*}{ Tratamento } & \multicolumn{2}{c}{ Produtividade de soja $\left(\mathrm{kg} \mathrm{ha}^{1}\right)$} \\
\cline { 2 - 3 } & Safra 15/16 & Safra 16/17 \\
\hline Milheto & $3240,7 \mathrm{a}$ & $3613,5, \mathrm{ab}$ \\
Urochloa brizantha & $2321,0 \mathrm{ab}$ & $2627,2 \mathrm{~b}$ \\
Milho & $2283,9 \mathrm{ab}$ & $2869,2 \mathrm{ab}$ \\
Sorgo & $2055,5 \mathrm{~b}$ & $3771,2 \mathrm{a}$ \\
Girassol & $1592,6 \mathrm{~b}$ & $3208,5 \mathrm{ab}$ \\
Guandu & $2178,0 \mathrm{ab}$ & $3564,0 \mathrm{ab}$ \\
\hline $\mathrm{F}$ & & $3,72^{* *}$ \\
\hline CV(\%) & & 18,84 \\
\hline
\end{tabular}

Médias seguidas pelas mesmas letras não diferem estatisticamente entre si pelo teste Tukey $(p<0,005)$

O maior acúmulo de carbono na biomassa microbiana do solo (CBMS) deu-se com a utilização de feijão guandu em relação aos demais tratamentos, com exceção da área cultivada com girassol. O menor teor de CBMS foi encontrado no tratamento milheto (Tabela 3).

A taxa de respiração basal do solo foi superior no solo cultivado com sorgo em relação às áreas cultivadas com girassol e milheto. Já os teores de nitrogênio da biomassa microbiana do solo (NBMS), e atividade enzimática (desidrogenase e fosfatase ácida) não diferiram entre si, conforme o emprego das plantas de cobertura (Tabela 3 ). 
Tabela 3. Análise microbiológica do solo na profundidade $0-10 \mathrm{~cm}$ coletada no município de Presidente Bernardes - SP, 2017

\begin{tabular}{|c|c|c|c|c|c|}
\hline & CBMS & NBMS & Desidrogenase & RBS & Fosfatase ácida \\
\hline Iratamento & & $\mu g g^{-1}$ & & $\mathrm{mg} \mathrm{C}-\mathrm{CO}_{2} \mathrm{~kg}_{1}^{-1}$ solo $\mathrm{h}^{-}$ & $\mu \mathrm{g} \mathrm{h}^{-1} \mathrm{~g}^{-1}$ solo \\
\hline Milheto & $42,14 \mathrm{c}$ & 3,0 & 2,5 & $1,96 \mathrm{~b}$ & 217,9 \\
\hline $\begin{array}{l}\text { Urochloa } \\
\text { brizantha }\end{array}$ & 45,01 bc & 6,4 & 1,7 & $2,56 a b$ & 220,4 \\
\hline Milho & 47,42 bc & 7,2 & 1,9 & $2,99 a b$ & 225,4 \\
\hline Sorgo & 49,46 bc & 9,2 & 2,0 & $4,08 \mathrm{a}$ & 223,5 \\
\hline Girassol & $62,80 a b$ & 5,2 & 3,2 & $1,89 \mathrm{~b}$ & 225,5 \\
\hline Guandu & $74,10 \mathrm{a}$ & 4,0 & 2,1 & $2,82 a b$ & 224,9 \\
\hline $\mathrm{F}$ & $10,44^{* *}$ & $1,29^{\text {ns }}$ & $2,92^{\text {ns }}$ & $3,67^{*}$ & $0,86^{\text {ns }}$ \\
\hline C.V. (\%) & 12,39 & 57,74 & 24,34 & 26,68 & 2,59 \\
\hline
\end{tabular}

Médias seguidas pelas mesmas letras não diferem estatisticamente entre si pelo teste Tukey $(p<0,005)$

Os teores de matéria orgânica do solo (M.O.) e carbono orgânico do solo (C.O.) não apresentaram influencia com o manejo de plantas de entressafra para o cultivo da soja (Tabela 4). Já o quociente metabólico $\left(q \mathrm{CO}_{2}\right)$ que é a razão entre a respiração basal do solo e o CBMS apresentou maiores valores na área cultivada com sorgo em relação às áreas cultivadas com girassol e feijão guandu (Tabela 4).

Os valores obtidos de $q \mathrm{CO}_{2}$ foram menores após o cultivo de girassol e feijão guandu em relação ao cultivo de sorgo na entressafra da soja. E os valores de qMic que expressam quanto do carbono orgânico do solo está imobilizado na biomassa microbiana, a maior eficiência dos microrganismos na imobilização do carbono ocorreu após o cultivo de feijão guandu em relação ao cultivo dos demais tratamentos, com exceção do cultivo de girassol (Tabela 4).

Tabela 4. Análise microbiológica do solo na profundidade $0-10 \mathrm{~cm}$ coletada no município de Presidente Bernardes - SP, 2017

\begin{tabular}{|c|c|c|c|c|}
\hline Tratamento & M.O. & C.O. & $q \mathrm{CO}_{2}$ & qMic \\
\hline & \multicolumn{2}{|c|}{$\mathrm{g} \mathrm{dm}^{-3}$} & $\mathrm{mg} \mathrm{C}-\mathrm{CO}_{2} \mathrm{~g}^{-1} \mathrm{BMS}-\mathrm{Ch}^{-1}$ & $\mathrm{mg} \mathrm{C}-\mathrm{CO}_{2} \mathrm{mg} \mathrm{Cmic}^{-1}$ \\
\hline Milheto & 13,0 & 8,0 & $0,046 a b$ & $0,52 c$ \\
\hline Urochloa brizantha & 13,4 & 8,2 & $0,058 a b$ & $0,54 \mathrm{c}$ \\
\hline Milho & 12,5 & 7,9 & $0,063 a b$ & $0,59 c$ \\
\hline Sorgo & 11,3 & 6,8 & $0,083 \mathrm{a}$ & $0,73 \mathrm{bc}$ \\
\hline Girassol & 12,1 & 7,3 & $0,030 \mathrm{~b}$ & $0,86 a b$ \\
\hline Guandu & 11,0 & 6,6 & $0,037 b$ & $1,10 \mathrm{a}$ \\
\hline $\mathrm{F}$ & $1,09^{\text {ns }}$ & $3,69^{\text {ns }}$ & $4,90^{*}$ & $18,23^{* *}$ \\
\hline C.V. (\%) & 14,56 & 8,01 & 28,08 & 12,53 \\
\hline
\end{tabular}

Médias seguidas pelas mesmas letras não diferem estatisticamente entre si pelo teste Tukey $(p<0,005)$

\section{DISCUSSÕES}

Os efeitos promovidos pelas plantas de cobertura nos atributos químicos são bastante variáveis, dependendo de fatores como espécie utilizada, manejo, época de plantio e corte das plantas, tempo de permanência da palhada, condições ligadas ao tipo de solo e interação entre esses fatores (BORGES et al., 2014). Costa et al., (2006) avaliando dois sistemas de preparo de 
solo, plantio direto e convencional, constataram que o acúmulo de matéria orgânica foi superior no sistema de plantio direto pois não havendo o revolvimento e incorporação da palhada, promove decomposição lenta e a liberação gradual de nutrientes para a cultura seguinte.

O cultivo do guandu e girassol incrementaram os valores da BMS, o que reflete na melhoria da condição biológica do solo avaliado. Desta forma, os indicativos da BMS de carbono, por apresentarem uma rápida taxa de ciclagem reflete a mudança em resposta aos fatores abióticos e as práticas de manejo, antes mesmo que ocorram mudanças nos teores de M.O. (GAMARODRIGUES et al., 2005), reforçando que a BMS representa, portanto, a parte viva da matéria orgânica (GAMA-RODRIGUES; GAMA-RODRIGUES, 2008).

Segundo Daniel, Tiemann e Grandy (2014), a prática de rotação com a utilização de culturas de cobertura proporciona incrementos da ordem de $26 \%$ para o nitrogênio e $20 \%$ para o CBMS, o que reforça a importância do manejo rotacional para a melhoria da produtividade através do aumento da BMS, tornando uma das principais características para a construção de sistemas sustentáveis de produção, corroborando os dados encontrados neste experimento, com exceção do NBMS, já o incremento no CBMS foi averiguado após a introdução de espécies de outras famílias botânicas (fabaceae e asteraceae), como o guandu e o girassol, quebrando a sucessão de espécies da família poaceae.

Em experimento realizado por Amado et al., (2001), foi constatado que o revolvimento do solo com uma aração e duas gradagens, nos quatro primeiros anos da instalação do experimento, reduziu estoque de C.O. do solo, devido a ruptura de agregados do solo, e o mesmo voltou a crescer somente no quinto ano de cultivo, após diminuir a ruptura dos agregados do solo e consequentemente promover o acúmulo e estruturação da matéria orgânica. Assim, o solo onde o presente experimento foi instalado é de textura arenosa e apresenta pouca matéria orgânica, os benefícios de acúmulo de matéria orgânica e de não ruptura de agregados e carbono orgânico do solo possivelmente não foram observados, não refletindo em diferença significativa entre os tratamentos, ao passo que foi realizada a mecanização para o preparo de solo, mesmo que sobre sistema de semeadura direta.

Ao observar as taxas de respiração basal do solo, devemos recordar que elevadas taxas de respiração sugerem tanto distúrbios ecológicos, quanto altas produtividades num ecossistema (ISLAM, WEIL, 2000). Como visto nas tabelas 2 e 4, o maior índice de respiração do solo obtida na amostragem em 2017 na área cultivada com sorgo é a mesma área cuja maior produtividade da soja foi registrada na safra 2016/17.

Contudo, não se deve analisar um dado como a respiração basal do solo de forma isolada, pois dados complementares nos ajudam a esclarecer sobre os manejos adotados e sugerem índices de qualidade do solo, como $\mathrm{O} q \mathrm{CO}_{2}$, onde os menores teores sugerem economia na utilização de energia e, supostamente, reflete um ambiente mais estável ou mais próximo do seu estado de equilíbrio; ao contrário, valores elevados são indicativos de ecossistemas submetidos a alguma condição de estresse ou de distúrbio (TÓTOLA, CHAER, 2002). Ainda segundo estes autores, o aumento em qMic indica se o conteúdo de carbono está se mantendo estável ou variando de acordo com as condições impostas ao sistema, com isto temos que a utilização de guandu e girassol foram responsáveis por aumento na qualidade do solo, aumentando a eficiência dos microorganismos ali presentes em transformar a matéria orgânica e incorporar carbono no solo.

A atividade de diversas enzimas pode ser influenciada pela natureza da cobertura vegetal, (DICK et al., 1996). porém a atividade enzimática não foi influenciada neste estudo, conforme a utilização de plantas de cobertura e adubo verde na entressafra da soja. As fosfatases são correlacionadas com a deficiência de P crescimento das plantas (BALOTA et al., 2013), como visto no trabalho, os resultados de $P$ na tabela 1 , bem como os resultados enzimáticos da fosfatase ácida na camada de $0-10 \mathrm{~cm}$, não sofreram influencia do uso das plantas de entressafra. 


\section{CONCLUSÃO} guandu.

A atividade microbiológica do solo apresentou melhorias após o cultivo de girassol e feijão

A produtividade da soja foi influenciada pelo uso de plantas de entressafra, apresentando incremento após milheto no primeiro ano e após sorgo no segundo ano de cultivo.

Os parâmetros de fertilidade do solo não foram influenciados com o uso das plantas de entressafra para a cultura da soja.

\section{REFERÊNCIAS}

AMADO, T. J. C. et al., Potencial de culturas de cobertura em acumular carbono e nitrogênio no solo no plantio direto e a melhoria da qualidade ambiental. R. Bras. Ci. Solo. n. 25: 189 - 197, 2001.

ANDERSON, T.H.; DOMSCH, K.H. The metabolic quotient for $\mathrm{CO}_{2}\left(q \mathrm{CO}_{2}\right)$ as a specific activity parameter to assess the effects of environmental conditions, such as $\mathrm{pH}$, on the microbial biomass of forest soils. Soil Biology \& Biochemistry, v.25, p.393-395, 1993. https://doi.org/10.1016/0038$\underline{0717(93) 90140-7}$

BALOTA, E. L.; et al. Enzimas e seu papel na qualidade do solo. In: Topicos em ciência do solo. Viçosa - MG. vol. 8, p. 189 - 249, 2013.

BORGES, W. L. B.; et al. Absorção de nutrientes e alterações químicas em latossolos cultivados com plantas de cobertura em rotação com soja e milho, R. Bras. Ci. Solo, 38:252-261, 2014. https://doi.org/10.1590/S0100-06832014000100025

BURNS, R. G. Enzymes in soil: Some theoretical and praticial considerations. In: BURNS, R. G., Ed. Soil enzymes. New York, Academic Press. p. 295 - 339. 1978.

COSTA, E. A. et al. Qualidade do solo submetido a sistemas de cultivo com preparo convencional e plantio direto. Pesq. Agropec. Bras. V. 41, n. 7, p. 1185 - 1191, 2006. https://doi.org/10.1590/S0100-204X2006000700016

COSTA, G. D.; et al. Influência da adubação nos atributos microbiológicos do solo na produção de milho silagem, III Reunião Paranaense de Ciência do Solo, Londrina - PR, 2013.

CASIDA JÚNIOR, L. E.; et al. Soil dehydrogenase activity. Soil Sci., 98: 371 - 376, 1964. https://doi.org/10.1097/00010694-196412000-00004

DANIEL, M. D.; TIEMANN, L. K.; GRANDY, A. S. Does agricultural crop diversity enhance soil microbial biomass and organic matter dynamics? A meta-analysis. Ecological Applications, v. 24, n. 3, p. 560-570, 2014. https://doi.org/10.1890/13-0616.1

DICK, R.P.; et al. Soil enzyme activities and biodiversity measurements as integrative microbiological indicators. In: DORAN, J.W. \& JONES, A.J., eds. Methods for assessing soil quality. Madison, Soil Science Society of America, p.247-272. (SSSA Special Publication, 49). 1996.

EMBRAPA - Empresa Brasileira de Pesquisa Agropecuária. Sistema brasileiro de classificação de solos. 3.ed. Brasília, 353p. 2013. 
FERREIRA, A. D. S., et al. Utilização de microondas na avaliação da biomassa microbiana do solo. Revista Brasileira de Ciência do Solo, 23(4), 991-996. 1999. https://doi.org/10.1590/S0100$\underline{06831999000400026}$

GAMA-RODRIGUES, E. F. et al. Nitrogênio, carbono e atividade da biomassa microbiana do solo em plantações de eucalipto. Revista Brasileira de Ciência do Solo, v. 29, p. 893-901, 2005. https://doi.org/10.1590/S0100-06832005000600007

GAMA-RODRIGUES, E. F.; GAMA-RODRIGUES, A. C. Atributos químicos e microbianos de solos sob diferentes coberturas vegetais no norte do Estado do Rio de Janeiro. Revista Brasileira de Ciência do Solo, v. 32, n. 4, p. 1521-1530, 2008. https://doi.org/10.1590/S0100-06832008000400016

ISLAM, K.R.; WEIL, R.R. Land use effects on soil quality in a tropical forest ecosystem of Bangladesh. Agriculture Ecosystems and Environment, v.79, p.9-16, 2000. https://doi.org/10.1016/S0167-8809(99)00145-0

JENKINSON, D. S.; POWLSON, D. S. The effects of biocidal treatments on metabolism in soil-V: a method for measuring soil biomass. Soil biology and biochemistry, v. 8, n. 3, p. 209-213, 1976. https://doi.org/10.1016/0038-0717(76)90005-5

RAIJ, B. V. et al. Análise química para avaliação da fertilidade de solos tropicais. Campinas: Instituto Agronômico, 2001. 285 p.

SILVA, M. B.; et al. Atributos biológicos do solo sob influência da cobertura vegetal e do sistema de manejo, Pesq. agropec. bras., Brasileira, v.42, n.12, p. 1755 -1761, dez. 2007.

SPARLING, G.P. Ratio of microbial biomass carbon to soil organic carbon as a sensitive indicator of changes in soil organic matter. Aust. J. Soil Res., 30: 195-207, 1992. https://doi.org/10.1071/SR9920195

TABATABAI, M. A.; BREMNER, J. M. Use of p-nitrophenyl phosphate for assay of soil phosphatase activity. Soil biology and biochemistry, v. 1, n. 4, p. 301-307, 1969. https://doi.org/10.1016/0038$\underline{\text { 0717(69)90012-1 }}$

TÓTOLA, M.R.; CHAER, G.M. Microrganismos e processos microbiológicos como indicadores da qualidade do solo. In: ALVAREZ VENEGAS, V.H.; et al. (Ed.). Tópicos em ciência do solo. Viçosa: Sociedade Brasileira de Ciência do Solo, p.195-276. 2002.

VAN OS, G. J.; GINKEL, J. H. Suppression of Pythium root rot in bulbous Iris in relation to biomass and activity of the soil microflora. Soil Biology \& Biochemistry, London, v. 33, n. 11, p. 1447-1454, set. 2001. https://doi.org/10.1016/S0038-0717(01)00053-0 